\title{
EXERCISE-INDUCED NT-PRO BNP SECRETION IN HYPERTENSIVE PATIENTS WITHOUT HEART FAILURE CAN DIAGNOSE THE SUBCLINICAL LEFT VENTRICLE DYSFUNCTION
}

\author{
Nicolae Păun ${ }^{1,2}$, Ingrid Joanna Sinelli ${ }^{3}$, Camelia Nicolae ${ }^{1,2}$, Ioan Tiberiu Nanea ${ }^{1,2}$, \\ Corneliu Toader ${ }^{1,3}$ \\ "'Carol Davila" University of Medicine and Pharmacy, Bucharest \\ 2"Prof. Dr. Th. Burghele" Clinical Hospital, Bucharest \\ ${ }^{3}$ National Institute of Neurology and Neurovascular Diseases \\ Corresponding author: Nicolae Păun \\ E-mail: nicpaun66.np@gmail.com
}

\begin{abstract}
Hypertension is one of the main risk factors for developing left ventricle failure. The study was conducted at outpatient Clinic - Medlife, Memorial Hospital. It was an observational study. We analyzed the exercise-induced secretion of NT-pro BNP in hypertensive patients with normal ejection fraction and no symptoms or signs of heart failure. Comparing the levels of NT-pro BNP before and after exercise proved to be a good mean for diagnosing left ventricular dysfunction (LVD) in hypertensive patients with left ventricular remodeling.
\end{abstract}

Keywords: hypertension, left ventricle dysfunction, left ventricle remodeling, NT-pro BNP, exercise.

\section{Rezumat}

Hipertensiunea arterială este unul dintre principalii factori de risc pentru insuficiența ventriculară stângă. Studiul a fost efectuat la Clinica Medlife, Memorial Hospital și a fost un studiu observațional. Am analizat concentrația palsmatică a NT-pro BNP după efort la pacienții hipertensivi cu FE păstrată și fără semne sau simptome de insuficiență cardiacă. Compararea concentrației NT-pro BNP înainte și după efort s-a dovedit a fi o bună metodă pentru diagnosticul disfuncției de VS la pacienții hipertensivi cu remodelare ventriculară.

Cuvinte cheie: hipertensiune arterială, disfuncție de ventricul stâng, remodelare ventriculară, NT-pro BNP, efort. 


\section{INTERNAL}

\section{Original Papers}

\section{Introduction}

Early diagnosing of heart failure (HF) is the main goal in patients with cardiovascular risk factors. In many hypertensive patients the myocardium may suffer important structural changes, such as unhealthy hypertrophy and interstitial fibrosis. This will lead to left ventricle dysfunction (LVD) and finally to overt left ventricle failure (LVF). The sooner the LVD is diagnosed and treated, the later the LVF will arise ${ }^{(1,2)}$.

$\mathrm{N}$-terminal pro-brain natriuretic peptide (NTpro BNP) emerged as the best biomarker for diagnosing acute heart failure, for guidedtreatment and fallow-up of the patients with overt heart failure ${ }^{(3,4,5)}$.

NT-pro BNP was also used as a possible biomarker for estimating the exercise capacity in patients with heart failure ${ }^{(6)}$. Those studies only used the levels of NT-pro BNP in blood at rest.

Miguel Rivera and co. demonstrated in a study on patients with dyspnea, that NT-pro BNP was higher in hypertensive patients compared with normotensive patients. They also found that only hypertensive patients with diastolic dysfunction had higher values of NT-pro BNP ${ }^{(7)}$. But M Rivera analysed only the NT-pro BNP at rest and he included hypertensive and normotensive patients regardless the left ventricle ejection fraction, or any other confounding factors which might have influenced the level of NT-pro BNP, such as obesity, age, chronic renal disease.

\section{Objectives}

We wanted to see whether hypertensive patients with no symptoms or signs of heart failure and with normal ejection fraction (EF) at both rest and effort, can be diagnosed as having exercise-induced LVD. This would be defined as a subclinical, stage $B$, left ventricle dysfunction. This way we compared the levels in blood of NT-pro BNP both, before and after exercise.

\section{Methods}

We did an observational study with hypertensive patients having drug-controlled BP. The study was conducted at the outpatients Clinic, Medlife - Memorial Hospital as an observational study.

We randomly included hypertensive patients regardless the grade of their $\mathrm{BP}$ at the moment when the diagnosis was made, as long as the figures of blood pressure were within normal limits for the past three months, according to their home recordings. We excluded from our study patients with $\mathrm{AF}$ and conduction abnormalities, moderatesevere valvulopathies, cardiomyopathies and known ischemic heart disease Also, there were excluded patients with advanced 


\begin{tabular}{|c|c|c|}
\hline Patient & Age & Gender \\
\hline 1 & 57 & $M$ \\
\hline 2 & 65 & $M$ \\
\hline 3 & 58 & $F$ \\
\hline 4 & 58 & $\bar{M}$ \\
\hline 5 & 66 & $F$ \\
\hline 6 & 45 & $M$ \\
\hline 7 & 63 & $M$ \\
\hline 8 & 54 & $F$ \\
\hline 9 & 50 & $\mathrm{M}$ \\
\hline 10 & 47 & $F$ \\
\hline 11 & 55 & $\bar{M}$ \\
\hline 12 & 70 & $\bar{M}$ \\
\hline 13 & 68 & $F$ \\
\hline 14 & 57 & $M$ \\
\hline 15 & 68 & $\bar{M}$ \\
\hline 16 & 61 & $F$ \\
\hline 17 & 55 & $M$ \\
\hline 18 & 66 & $M$ \\
\hline 19 & 72 & $M$ \\
\hline 20 & 67 & $\bar{M}$ \\
\hline
\end{tabular}

Table 1. Patients' data

\begin{tabular}{|c|c|c|c|}
\hline Patient & BNP -1 & BNP - 2 & BNP - 3 \\
\hline 1 & 110 & 150 & 150 \\
\hline 2 & 158 & 271 & 272 \\
\hline 3 & 119 & 113 & 165 \\
\hline 4 & 114 & 116 & 184 \\
\hline 5 & 136 & 192 & 279 \\
\hline 6 & 95 & 123 & 155 \\
\hline 7 & 238 & 387 & 470 \\
\hline 8 & 248 & 282 & 202 \\
\hline 9 & 157 & 168 & 212 \\
\hline 10 & 78 & 82 & 80 \\
\hline 1 & 131 & 194 & 107 \\
\hline 12 & 172 & 333 & 107 \\
\hline 13 & 157 & 155 & 480 \\
\hline 14 & 124 & 205 & 152 \\
\hline 15 & 214 & 288 & 377 \\
\hline 16 & 184 & 337 & 308 \\
\hline 17 & 147 & 187 & 218 \\
\hline 18 & 238 & 344 & 475 \\
\hline 19 & 114 & 247 & 245 \\
\hline 20 & 325 & 372 & 484 \\
\hline
\end{tabular}

Table 2. NT-pro BNP concentration

\begin{tabular}{|l|l|l|l|}
\hline & BNP -1 & BNP -2 & BNP -3 \\
\hline BNP -1 & - & 0,007 & 0,004 \\
\hline BNP -2 & 0,007 & - & - \\
\hline BNP -3 & 0,004 & - & - \\
\hline
\end{tabular}

Table 3A. Statistics results for all patients(t-test; $p$ values)

\begin{tabular}{|l|l|l|}
\hline & LV remodeling & LV normal \\
\hline BNP -1 vs BNP -2 & 0,007 & 0,0505 \\
\hline BNP -1 vs BNP -3 & 0,002 & 0,0507 \\
\hline
\end{tabular}

Table 3B. Statistics results for subgroup of patients (t-test; $p$ values) 


\section{INTERNAI}

\section{Original Papers}

renal disease (stage $>$ II), lung diseases or hepatic diseases. We also excluded patients on medication which can modify the ECG morphology as Gheorghe GS recently demonstrated $^{(21)}$. Those patients who could not perform the exercise ECG test or showed ischemic abnormalities during the test, were excluded too. Finally, we included 20 patients (12 men, age 45-70), half of which had left ventricular remodeling, defined as increased myocardial mass $^{(9)}$ (Table 1 ).

All patients had a rest ECG, a rest and after exercise echocardiography and exercise treadmill ECG test done. The exercise ECG test was done according to Bruce protocol ${ }^{(8)}$. The echocardiography measurements were done according the European Society of Cardiology ${ }^{(9)}$. We measured the levels of NTpro BNP 3 times: before the exercise test (BNP-1), immediately after the test (BNP-2) and $24 \mathrm{~h}$ after the test (BNP-3) (Table 2).

\section{Statistical analysis}

Though the data we analyzed were skewed, they still showed a normal distribution according to Kolmogorov-Smirnov test. At the same time we looked at the homogeneity of variance for all sets of data through the Levene's test. All sets of data met the criteria for homogeneity of variance with $\mathrm{F}$ ratio value 0,663 for BNP-1 data, 0,869 for BNP-2 data and 1,3578 for BNP-3 data. All of these, allowed us to perform the t-test for comparing the 3 sets of levels of NT-pro BNP. In order to see which level of NT-pro BNP is more significant we compared both BNP-1 with BNP-2 and BNP-1 with BNP-3 (Table 2). In our study the Ho stated that there was no difference between the values of NT-pro BNP analysed, at an alpha value $<0,05$. The statistics showed a statistically significant increase of NT-pro BNP after exercise, regardless the moment of measuring ( $p$ value of 0,007 for comparing BNP-1 vs BNP-2 and 0,004 for comparing BNP-1 vs BNP-3), leading to conclusion that the Ho can be rejected.

In order to see the clinical significance of the increased levels of NT-pro BNP after the exercise, regardless of the sample size, we looked at the effect size. It showed large size effect with very good clinical significance values for each comparison: BNP-1 vs BNP-2 with Glass's delta $=1,04$, and BNP-1 vs BNP-3 with Glass's delta $=1,48$ (Table 3A).

When we looked at the two subgroups of patients, those with left ventricular remodeling and those without left ventricular remodeling, we noticed that the only statistically significant increase in NT-pro BNP after exercise was seen in the former (Table 3B).

\section{Discussion}

Heart failure with either reduced or preserved ejection fraction, is the main cause of hospital 
admission related to cardio-vascular diseases in the developed countries ${ }^{(10)}$. On the other hand, hypertension, which is the most frequent cardiovascular disease, if left untreated, can lead to heart failure ${ }^{(1,2)}$. Over the past decades, there has been introduced many antihypertensive drugs that have proved to be very efficient in keeping the blood pressure within normal limits. In spite of that, many hypertensive patients finally develop heart failure ${ }^{(11)}$.

We have several means to diagnose or to estimate the left ventricle function after exercise, like catheterization and echocardiography. Each of them has its own advantages, but most importantly some disadvantages. Measuring the levels of NTpro BNP in blood is objective, more precise, being independent of the patient and the doctor and non-invasive.

Increased exercise-induced NT-pro BNP secretion has already demonstrated in both normal subjects after strenuous exercise and in patients with heart failure after aerobic type of exercise ${ }^{(12)}$.

Based only on the levels of NT-pro BNP in blood at rest which was fallowed for 6 months, the study LIFE demonstrated that hypertensive patients, especially those with left ventricle hypertrophy, are at greater risk for CV events ${ }^{(13)}$. Guenter Neumayr and co. showed that the NT-pro BNP increased statistically significant after strenuous exercise in healthy recreational cyclists and how it changed over time after the exercise ${ }^{(14)}$. To our knowledge there is no study looking at variations of NT-pro BNP in hypertensive patients without heart failure, before and after the exercise test.

Conflicting data have been published in literature regarding the relationship between NT-pro BNP levels and LVD ${ }^{(17,18,19)}$. Anyhow, these studies used only the values of NT-pro
BNP at rest in attempting to predict whether there is or is not LVD.

The authors of this study wanted to see if measuring the levels of NT-pro BNP can provide strong data for diagnosing very early the left ventricle dysfunction in hypertensive patients. This way we could be able to find as soon as possible in the natural history of hypertension those patients at the highest risk for developing left ventricle dysfunction. This group of hypertensive patients should get a more intense antihypertensive treatment and be more carefully followed-up than the other hypertensive patients.

After comparing the values of NT-pro BNP before and after exercise we found statistically significant increased values of NT-pro BNP after exercise. We measured 2 values of NT-pro BNP after exercise: BNP-2 correlates with the deposits of BNP within the cytoplasm of myocites, ready to be released whenever there is an increased in myocardial wall stress; BNP-3 correlates with the de novo synthesis of BNP in myocites after increasing of the myocardial wall stress ${ }^{(15,16)}$. We noticed that in some patients the highest increase of NT-pro BNP was immediately after the exercise (BNP-2), while in other patients the highest increased was latter, that is 24 hours after exercise (BNP-3). There even were few patients with unexpected response to exercise, namely with decreased values of NT-pro BNP after exercise.

Both sets of data, BNP-2 and BNP-3, showed a statistically significant increase of NT-pro BNP (Table 3A). These results raise the question whether they are clinically significant or not. On the other hand, we tried to see if there was a confounding factor which can explain these results.

In order to see the clinically significance of the increased levels of NT-pro BNP after exercise, we looked at the effect size. The 


\section{INTERNAL}

\section{Original Papers}

calculations showed large effect size in both comparison (BNP-1 vs BNP-2 and BNP-1 vs BNP-3). This allowed us to conclude that the results measured after the exercise have a good and very good clinical significance, so they have a clear clinical importance.

But when we looked at the 2 different types of patients independently, we noticed that only those with left ventricular remodeling had a statistically significant increase of NT-pro BNP after exercise. While those without left ventricular remodeling had no statistically significant results for NT-pro BNP after exercise. The hypertensive patients with left ventricular remodeling were the only ones who accounted for the results obtained for the entire group of studied patients, acting as a confounding factor in our calculations.

\section{Limits}

We consider that our study brought up an important issue related to diagnosing some of the hypertensive patients at high risk of developing LVD, but the sample size of the study was small which can bias the results. That is why, our results have to be confirmed by larger studies, which can also help in establishing a cut-off value for NT-pro BNP.

On the other hand, we conducted only an observational study. In order to validate our conclusions a prospected study would be appropriate.

\section{Conclusion}

Measuring the post-exercise NT-pro BNP in hypertensive patients with normal EF and no symptoms of heart failure, proved to be a more precise, objecting and reliable means of diagnosing the subclinical left ventricle dysfunction.

The subgroup of hypertensive patients with left ventricular remodeling are at the greatest risk of developing diastolic dysfunction. It is in this type of patients in which our study demonstrated that the measuring of exercise-related NT-pro BNP is especially useful for revealing the subclinical diastolic dysfunction. This type of patients should have hypertension treated more aggressively with clear benefit in terms of developing in time overt heart failure and adverse CV events $^{(20)}$.

\section{References}

1. Veeran Subramaniam, Gregory Y H Lip, "Hypertension to heart failure: a pathophysiological spectrum relating blood pressure, drug treatments and stroke"; Expert Rev Cardiovasc Ther. 2009 Jun; 7(6):70313. doi: 10.1586/erc.09.43

2. Arun Kannan, Rajesh Janardhanan, "Hypertension as a risk factor for “Curr Hypertens Rep. 2014 Jul;16(7):447.doi: 10.1007/s11906-014-0447-7

3. Fabian Knebel, Ingolf Schimke, Kathleen Pliet, Sebastian Schattke, Salim Martin, Adrian C Borges, Gert Baumann; "NT-pro BNP in acute heart failure: correlationwith invasively measured. 2005 Jun;11(5 Suppl):S38-41. doi: 10.1016/j.cardfail.2005.04.012.

4. Frederick A. Masoudi, MD, MSPH, FACC, FAHA 
reviewing Januzzi JL Jr et al."Ëmpiric NT-pro BNP cut points for diagnosing acute heart failure"; J Am Coll Cardiol 2018 Mar 20 McCullough PA and Kluger AY. J Am Coll Cardiol 2018 Mar 20

5. Acute and chronic heart failure guidelines; $E H J$ (2016) 37 (27):2129-2200 - https://doi.org/10.1093 leurheartj/ehw128

6. Milos Parovic, and all; "NT-pro BNP is a weak indicator of cardiac function and haemodynamic response to exercise in chronic heart failure"; ESC Heart Fail. 2019 Apr;6(2):449454. doi: 10.1002/ehf2.12424. Epub 2019 Feb 20.

7. Miguel Rivera, and all; "NT-pro BNP levels and hypertension. Their importance in diagnosis of heart failure"; Rev Esp Cardiol. 2004 May; 57(5):396-402.

8. Gerald F. Fletcher, and all; "Exercise standards for testing and training A scientific statement from the American Heart Association", Circulation, Volume 128, Issue 8, 20 August 2013, Pages 873-934, https://doi.org/ 10.1161/CIR.0b013e31829b5b44

9. Roberto M. Lang, and all; "Recommendations for Cardiac Chamber Quantification by Echocardiography in Adults: An Update from the American Society of Echocardiography and the European Association of Cardiovascular Imaging", European Heart Journal Cardiovascular Imaging (2015) 16, 233271 doi:10.1093/ehjci/jev014

10. Emmanuel Akintoye, and all; "National trends in admission and In-hospital mortality of patients with heart failure in the United States (2001 2014)"; JAMA, 29 Nov 2017, vol. 6, nr. 12; https://doi.org/10.1161/ JAHA. 117.006955

11. Gyu Chul Oh \& Hyun-Jai Cho, and all; "Blood pressure and heart failure"; Clinical Hypertension volume 26, Article number: 1 (2020)

12. Hamasaki $H$, "The effects of exercise on Natriuretic Peptides in individuals without heart failure", Sports (Basel), June 2016

13. Olsen M.H., and all." N-terminal pro-brain natriuretic peptide predicts cardiovascular events in patients with hypertension and left ventricular hypertrophy" A LIFE study. J. Hypertens. 2004;22:15971604. doi: 10.1097/01.hjh.0000125451.28861.2a.

14. Neumayr G., and all; "Effect of competitive marathon cycling on plasma $\mathrm{N}$-terminal pro-brain natriuretic peptide and cardiac troponin $T$ in healthy recreational cyclists". Am. J. Cardiol. 2005;96:732735. doi: 10.1016/j.amjcard.2005.04.054

15. Shihui Fu, and all; "Synthesis, secretion, function, metabolism ad application of natriuretic peptides in heart failure", Journal of Biological Engineering volume 12, Article number: 2 (2018)

16. Braunwald $E$, "Medical progress: Biomarkers in heart failure", NEJM 2018; 358; 2148-2159

17. Eun-Hee Nah, and all; "Plasma NT-pro BNP levels associated with cardiac structural abnormalities in asymptomatic health examinees with preserved ejection fraction: a retrospective cross-sectional study", BMJ Open. 2019 Apr 20;9(4):e026030. doi: 10.1136/ bmjopen-2018-026030.

18. M N Islam, and all; "Association of diastolic dysfunction with $N$-terminal pro-B-_type natriuretic peptide level in heart failure patients with preserved ejection fraction"; Mymensingh Med J. 2019 Apr;28(2):333-346.

19. Hyungseop Kim, and all; "The correlation of left atrial volume index to the level of N-terminal pro-BNP in heart filure with a preserved ejection fraction"; Echocardiography. 2008 Oct;25(9):961-7. doi: 10.1111/j.1540-8175.2008.00717.x. Epub 2008 Sep 2

20. Olsen MH, Wachtell K, Tuxen C, Fossum E, Bang LE, Hall C, Ibsen H, Rokkedal J, Devereux RB, Hildebrandt PR.J "Opposite effects of losartan and atenolol on natriuretic peptides in patients with hypertension and left ventricular hypertrophy: a LIFE substudy".;.J Hypertens. 2005 May;23(5):1083-90. doi: 10.1097/ 01.hjh.0000166851.18463.85.

21. Gheoeghe ACD, Ciobanu A, Hodorogea AS, Radavoi $G D$, Jinga V, Nanea IT, Gheorghe GS; "Evolution of Electrocardiographic Repolarisation Parameters During Antiandrogenic Therapy in Patients with Prostate Cancer and Hypogodadism" Cardiovasc Toxicol 2020, 20(4): 390-400.Doi 10.1007/s12012-020-09566-6 